\title{
The Infralimbic Cortex Bidirectionally Modulates Mesolimbic Dopamine Neuron Activity via Distinct Neural Pathways
}

\author{
Mary H. Patton, ${ }^{\star}$ Brandon T. Bizup, ${ }^{\star}$ and Anthony A. Grace \\ Departments of Neuroscience, Psychiatry and Psychology, University of Pittsburgh, Pittsburgh, Pennsylvania 15260
}

The ventral tegmental area (VTA) has been implicated in a number of psychiatric disorders, including schizophrenia, depression, and bipolar disorder. One major regulator of the mesolimbic dopaminergic system is the medial prefrontal cortex (mPFC), which makes direct and indirect connections to the hippocampus and amygdala, as well as directly to the VTA. The mPFC is comprised of two subregions: the infralimbic and prelimbic cortices (ilPFC and plPFC). However, the specific roles of these subregions in regulating VTA dopamine activity have remained unclear. In this study, we aim to clarify this role and to examine the divergent neuranatomical circuits by which the mPFC regulates VTA activity. Using in vivo extracellular recordings in rats, we tested the effects of pharmacological activation (with NMDA) and inactivation (with TTX) of the ilPFC and plPFC on dopamine neuron activity, and tested the roles of the ventral subiculum (vSub) and basolateral amygdala in this process. We found that the ilPFC exerts a bidirectional control of VTA dopamine neurons, which are differentially modulated through the vSub and the basolateral amygdala. Specifically, activation or inactivation of the ilPFC attenuated or activated dopamine neuron population activity, respectively. Furthermore, dopamine activation depended on the ventral hippocampus and inactivation on the amygdala. In contrast, only inactivation of the plPFC altered dopamine neuron activity. These data indicate that the MPFC has the ability to uniquely fine-tune dopaminergic activity in the VTA. Furthermore, the data presented here suggest that the ilPFC may have a role in the pathophysiology of psychiatric disorders.

\section{Introduction}

Mesolimbic dopamine (DA) neurons and the ventral tegmental area (VTA) are commonly associated with goal-directed behavior and reward valuation. In addition, aberrant midbrain DA circuitry is implicated as a contributing factor in many psychiatric disorders. For instance, hyper-reactivity of the dopaminergic system and the VTA has been associated with schizophrenia (Lodge and Grace, 2007), amphetamine hyperactivity (Lodge and Grace, 2008b; Daberkow et al., 2013; Espana and Jones, 2013), and mania (Lyon and Satz, 1991; Park and Kang, 2013). In contrast, anhedonia, a core symptom of major depressive disorder and bipolar disorder, has been linked with the DA system and has been associated with a decrease in DA activity, leading to a de-

\footnotetext{
Received June 10, 2013; revised Sept. 7, 2013; accepted Sept. 12, 2013.

Author contributions: M.H.P., B.T.B., and A.A.G. designed research; M.H.P., B.T.B., and A.A.G. performed research; M.H.P., B.T.B., and A.A.G. analyzed data; M.H.P., B.T.B., and A.A.G. wrote the paper.

This work was supported by United States Public Health Service Grant MH57440 to A.A.G. We thank Pauline Belujon for helpful guidance throughout the study and writing process, Katherine Gill for statistical help, and Niki MacMurdo for technical assistance.

A.A.G. has received research grants from Lilly and Lundbeck; is on the advisory board of Roche and Ascubio; and received honoraria from Pfizer, Merck, Takeda, Dainippon Sumitomo, and Lilly. The remaining authors declare no conflict of interest.

${ }^{*}$ M.H.P. and B.T.B. contributed equally to this work.

Correspondence should be addressed to Dr. Anthony A. Grace, Department of Neuroscience, A210 Langley Hall, University of Pittsburgh, Pittsburgh, PA 15260. E-mail: GraceAA@pitt.edu.

M.H. Patton's present address: Department of Physiology, University of Maryland, Baltimore, Baltimore, MD 21201.

DOI:10.1523/JNEUROSCI.2449-13.2013

Copyright $\odot 2013$ the authors $\quad 0270-6474 / 13 / 3316865-09 \$ 15.00 / 0$
}

crease in motivation for rewarding stimuli (Wise et al., 1978; Wise, 2008; Treadway and Zald, 2011).

A major regulator of the DA system is the prefrontal cortex (PFC). Two major subdivisions of the medial PFC (mPFC), the infralimbic (ilPFC) and the prelimbic (plPFC) cortices, have direct projections to the VTA (Sesack and Carr, 2002; Gabbott et al., 2005) as well as to other regions of the brain linked with control of mesolimbic DA, including the basolateral amygdala (BLA), the nucleus accumbens, and the entorhinal cortex-ventral subiculum system. Additionally, like the VTA, the $\mathrm{mPFC}$ has been implicated in psychiatric illnesses. Hyperactivity in Brodmann's area 25 (analogous to ilPFC in the rat) has been associated with depression (Mayberg et al., 2000; Keedwell et al., 2009), and area 32 (analogous to plPFC) is implicated in stimulant abuse (Koester et al., 2012). Moreover, studies have shown that these two subdivisions often have opposite effects on behavior (VidalGonzalez et al., 2006; Sierra-Mercado et al., 2011). However, studies into the manner by which the mPFC affects DA neuron activity have been inconclusive, possibly because investigators have not differentiated between these subdivisions (Overton et al., 1996; Lodge, 2011).

In addition to the $\mathrm{MPFC}$, other regions have been implicated in the pathophysiology of psychiatric disorders. Thus, there is evidence of altered hippocampus activity in major depressive disorder (Hoogenboom et al., 2012; Sexton et al., 2013), schizophrenia (Hu et al., 2013; Ledoux et al., 2013; Shan et al., 2013), and bipolar disorder (Lim et al., 2013). Postmortem studies of patients who suffered from major depressive disorder have found 
volumetric reductions in the hippocampus. Imaging studies in patients with bipolar disorder have found reductions in gray matter volume, although results regarding bipolar disorder are inconsistent and highly variant depending on when in the pathological cycle the studies are performed (Brooks et al., 2009; Bora et al., 2010; Singh et al., 2012). We have previously shown that aberrant hippocampal activity is linked to dopaminergic dysfunction in schizophrenia (Lodge and Grace, 2008a; Gill et al., 2011). Further, hyperactivity and increased amygdalar volume have been found in studies of major depressive disorder in humans (Kalia, 2005; Leppänen, 2006). Therefore, in this study, we aim to identify how the ilPFC and plPFC influence the activity of the VTA and determine how the BLA and ventral subiculum (vSub) may be implicated in that control.

\section{Materials and Methods}

Animals. All experiments were performed in accordance with the guidelines outlined in the USPHS Guide for Care and Use of Laboratory Animals and were approved by the Institutional Animal Care and Use Committee of the University of Pittsburgh. Adult male Sprague Dawley rats (82 rats total; $>300 \mathrm{~g}$ ) were anesthetized by injection of $8 \%$ chloral hydrate $(400$ $\mathrm{mg} / \mathrm{kg}$, i.p.), which was maintained by supplemental chloral hydrate injections as needed to suppress the hindpaw withdrawal reflex. Animals were placed in a stereotaxic frame (Kopf) with their core temperature maintained at $37^{\circ} \mathrm{C}$ via a temperature-controlled heating pad (Fine Scientific Tools).

Electrophysiology. Guide cannulae were placed into the either the plPFC or ilPFC (plPFC: anteroposterior $+3.7 \mathrm{~mm}$, mediolateral +0.5 $\mathrm{mm}$, dorsoventral $-2.5 \mathrm{~mm}$; see Fig. $1 A$; IL: anteroposterior $+2.7 \mathrm{~mm}$, mediolateral $+0.5 \mathrm{~mm}$, dorsoventral $-3.5 \mathrm{~mm}$; see Fig. $2 A$ ). In subsequent experiments, guide cannulae were placed in the ilPFC as well as the BLA (anteroposterior $-3.1 \mathrm{~mm}$, mediolateral $+5.0 \mathrm{~mm}$, dorsoventral $-6.6 \mathrm{~mm}$; see Fig. $3 A$ ) or vSub (anteroposterior $-6.0 \mathrm{~mm}$, mediolateral $+5.3 \mathrm{~mm}$, dorsoventral $-4.4 \mathrm{~mm}$; see Fig. $4 A$ ). Dulbecco's PBS (dPBS), NMDA $(0.75 \mu \mathrm{g}$ in $0.5 \mu \mathrm{l}$ of dPBS), and TTX ( $1 \mu \mathrm{M}$ in $0.5 \mu \mathrm{l}$ of dPBS) were obtained from Sigma-Aldrich and were administered through infusion cannulae that extended $1 \mathrm{~mm}$ past the tip of the guide cannulae, at a rate of $0.5 \mu \mathrm{l}$ per minute and left in place for $10 \mathrm{~min}$ to allow for adequate diffusion before extracellular recordings were initiated in the VTA.

Extracellular recording electrodes were pulled on a vertical electrode puller (PE-2) and the tip broken back under microscopic control to achieve an impedance between 6 and $14 \mathrm{M} \Omega$. Microelectrodes were filled with a $2 \%$ Chicago Sky Blue dye solution in $2 \mathrm{M} \mathrm{NaCl}$ and lowered through the VTA (beginning at: anteroposterior $-5.3 \mathrm{~mm}$, mediolateral $+0.6 \mathrm{~mm}$, dorsoventral -6.5 to $-9 \mathrm{~mm}$ ) via a hydraulic micropositioner (Kopf) in a nine track grid pattern to determine the overall population activity, which is defined as the number of spontaneously active DA neurons in six to nine total tracks (each track was separated by $200 \mu \mathrm{m}$ ). Spontaneously active DA neurons were identified using previously established electrophysiological criteria (Grace and Bunney, 1983; Ungless and Grace, 2012) and recorded with open filter settings (high pass = $10-50 \mathrm{~Hz}$; low pass $=16 \mathrm{kHz}$ ) for 3-6 min. Three characteristics of DA neuron activity were measured in the VTA: (1) the overall population activity as defined above, (2) the basal firing rate, and (3) the proportion of action potentials occurring in bursts, reported as the percentage of spikes in bursts. A burst is defined as the occurrence of two consecutive spikes with an interspike interval $<80 \mathrm{~ms}$, with the termination of a burst defined as two spikes with an interspike interval $>160 \mathrm{~ms}$ (Grace and Bunney, 1983, 1984).

Histology. At the cessation of each experiment, rats were overdosed with a lethal injection of chloral hydrate. Current was passed through the recording electrode, ejecting Chicago Sky Blue dye to verify its placement. Brains were removed and stored in $8 \%$ paraformaldehyde for $48 \mathrm{~h}$ before being transferred to a $25 \%$ sucrose solution for cryoprotection. Brains were then sliced coronally on a cryostat at $60 \mu \mathrm{m}$ thick and mounted onto gelatin-chromalum-coated slides. Slides were stained with a combination of cresyl violet and neutral red to identify cell bodies and placements were verified using a stereotaxic atlas (Paxinos and Watson, 2007). Only data from animals with accurate placements in all regions were kept for analysis.

Analysis. Electrophysiological data were gathered and analyzed using LabChart version 7 software. Additional measures (such as burst analysis and firing rate) were analyzed using NeuroExplorer version 4 . All data are represented as mean \pm SEM. Statistics were calculated using Sigma Plot version 11.0. For experiments involving one infusion site, a one-way ANOVA followed by a Holm-Sidak post hoc test was used to determine differences between groups, or a one-way ANOVA on ranks was used if the data were not normally distributed. For experiments involving two infusion sites, a two-way ANOVA followed by a Bonferroni post hoc $t$ test was used to determine differences between groups.

\section{Results}

\section{Inactivation of the prelimbic cortex decreased VTA DA neuron activity}

The influence of the plPFC on mesolimbic DA activity was tested by infusion of either NMDA or TTX into the plPFC and measuring overall population activity of VTA DA neurons. Rats that received plPFC vehicle infusions (dPBS; $n=10$ rats, 66 neurons) exhibited an average of $0.97 \pm 0.03$ spontaneously active DA neurons per electrode track, with an average firing rate of $3.7 \pm$ $0.2 \mathrm{~Hz}$ and $27.0 \pm 2.8 \%$ of action potentials fired in bursts (Fig. $1 B-D)$, which is consistent with previous findings (Lodge and Grace, 2007; Gill et al., 2011; Chang and Grace, 2013). Infusion of TTX in the plPFC ( $n=10$ rats, 40 neurons) significantly decreased spontaneous DA population activity in the VTA compared with controls (one-way ANOVA, $F_{(2,24)}=9.1, p=0.001$ : Holm-Sidak post hoc: $\left.t_{(18)}=3.5, p=0.002\right)$. Inactivation of the plPFC resulted in an average of $0.51 \pm 0.06$ cells/track (Fig. $1 B$ ), which represents an $\sim 50 \%$ decrease from control. TTX infusion did not, however, affect the firing rate of these neurons (Fig. 1C; $4.1 \pm 0.28 \mathrm{~Hz}$; one-way ANOVA, $\left.F_{(21,53)}=1.5, p=0.225\right)$ or the average burst firing (Fig. $1 D ; 24.1 \pm 3.5 \%$; one-way ANOVA, $\left.F_{(21,53)}=0.2, p=0.818\right)$. Thus, the only parameter altered by plPFC inactivation was overall spontaneous population activity. Activation of the plPFC by infusion of NMDA ( $n=7$ rats, 50 neurons) did not cause any significant changes in mesolimbic DA activity. The spontaneous population activity (Fig. 1B; $1.06 \pm$ 0.20 cells/track; one-way ANOVA, $F_{(2,24)}=9.1, p=0.001$; HolmSidak post hoc: $t_{(15)}=0.6, p=0.532$ ), firing rate (Fig. $1 C ; 3.5 \pm$ $0.2 \mathrm{~Hz}$; one-way ANOVA, $\left.F_{(21,53)}=1.5, p=0.225\right)$, and bursting activity (Fig. $1 D ; 25.8 \pm 3.6 \%$; one-way ANOVA, $F_{(2,153)}=0.2$, $p=0.818$ ) were not different from control values. Plotting the firing rate and burst firing for neurons in these groups in a histogram (Fig. $1 E, F$ ) did not show significant differences in distributions with the manipulations tested (Kolgomorov-Smirnoff test, $p>0.05)$

\section{Activation and inactivation of the infralimbic cortex have opposite effects on VTA dopamine activity}

To evaluate the effects of the ilPFC on midbrain DA neurons, the ilPFC was either activated (NMDA) or inactivated (TTX) before recording VTA DA neuron activity. Rats that received ilPFC vehicle infusions (dPBS; $n=5$ rats, 21 neurons) had an average of $0.93 \pm 0.13$ spontaneously active DA cells/track that fired at an average rate of $3.7 \pm 0.4 \mathrm{~Hz}$ with $28.2 \pm 6.4 \%$ of spikes occurring in bursts (Fig. $2 B-D$ ), again consistent with previous publications. Activation of the ilPFC with an infusion of NMDA $(n=5$ rats, 15 neurons) caused a significant decrease in DA population activity in the VTA compared with control (one-way ANOVA, $F_{(2,11)}=35.1, p<0.001$; Holm-Sidak post hoc: $t_{(8)}=3.2, p=$ 


\section{pIPFC infusions}

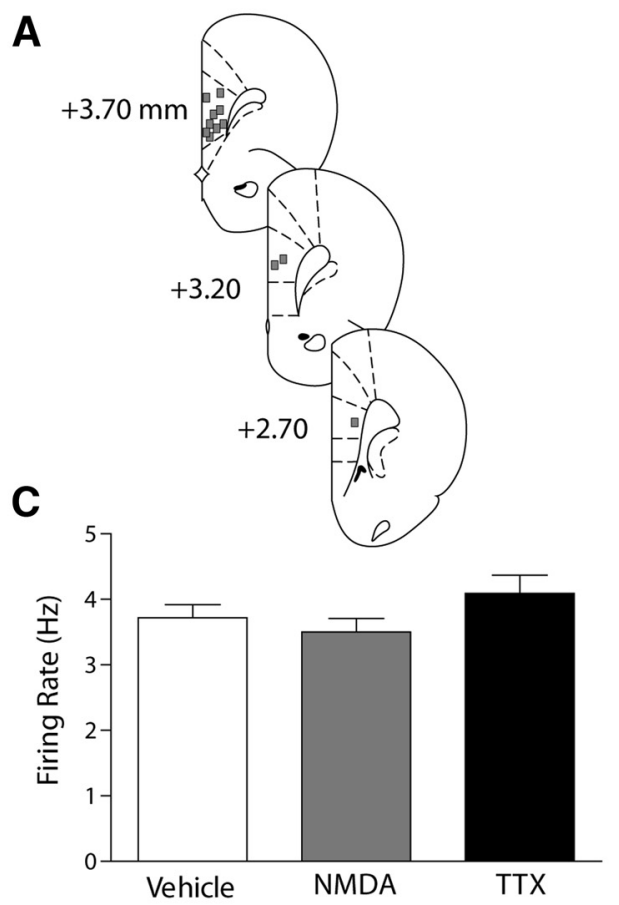

E

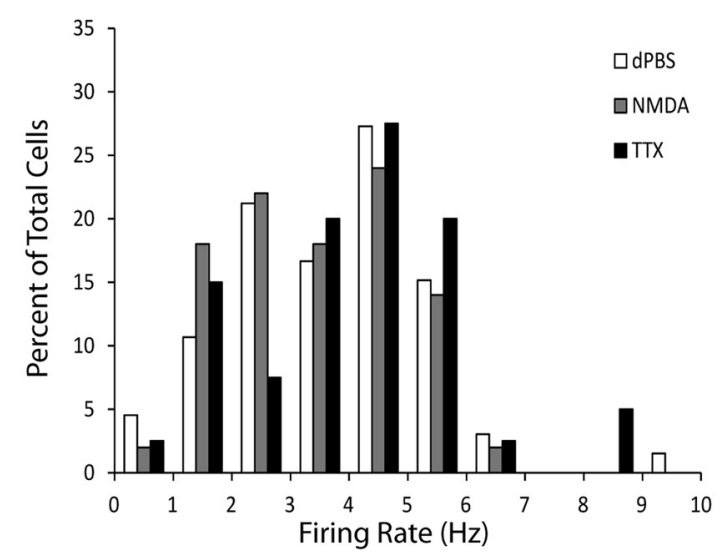

B

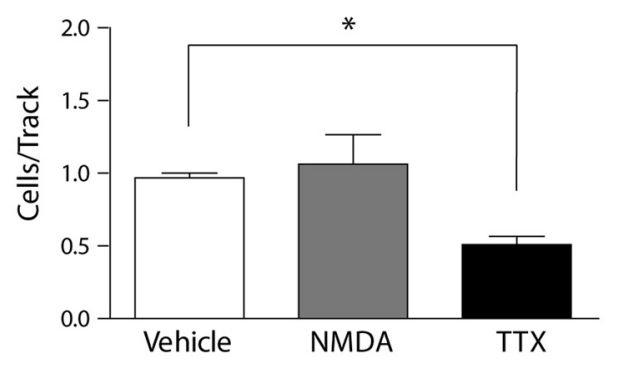

D

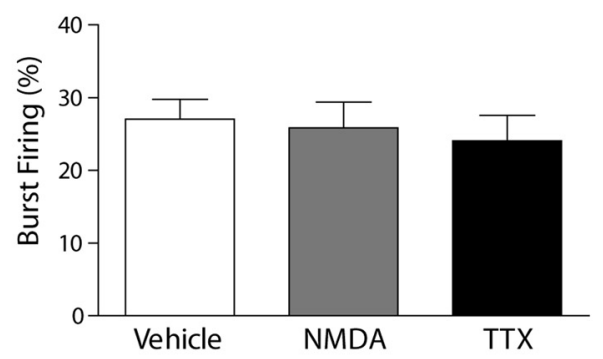

F

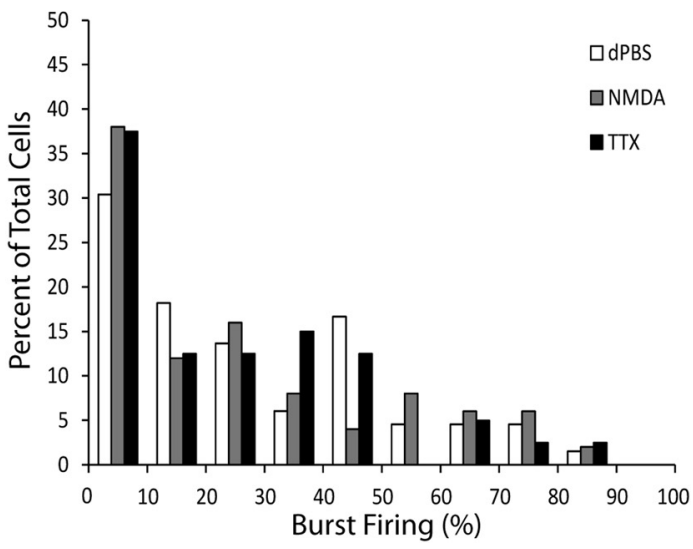

Figure 1. Inactivation of the pIPFC produces a selective attenuation of VTA DA neuron population activity. $\boldsymbol{A}$, Representation of histological placements of infusion cannulae into the pIPFC (squares, $50 \%$ shown). $\boldsymbol{B}$, Activating the pIPFC with NMDA did not change the number of spontaneously active dopamine neurons firing in the VTA (expressed as cells/track, gray bar) compared with infusion of vehicle (white bar). Inactivating the pIPFC with TTX resulted in a significant decrease in the number of spontaneously active dopamine cells in the VTA (black bar). $C$, $D$, The firing rate of spontaneously active dopamine cells and the percentage of cells firing in bursts were not affected by infusion of vehicle (white bar), NMDA (gray bar), or TTX (black bar) into the pIPFC. Distributions of firing rate $(\boldsymbol{E})$ and the percentage of burst firing $(\boldsymbol{F})$ were not affected significantly by infusions of NMDA or TTX (Kolgomorov-Smirnoff test). * $p<0.05$ (one-way ANOVA, Holm-Sidak post hoc test). $n=7-10 \mathrm{rats} /$ group; $n=40-66$ neurons/group. Data are represented as mean \pm SEM.

0.008). Spontaneous DA neuron activity in the VTA following pharmacological activation was decreased by $>50 \%$ to $0.38 \pm$ 0.10 cells/track (Fig. $2 B$ ). The average firing rate (Fig. $2 C ; 3.9 \pm$ $0.5 \mathrm{~Hz}$; one-way ANOVA, $\left.F_{(2,74)}=0.5, p=0.590\right)$ and percentage of spikes in bursts (Fig. $2 D ; 25.1 \pm 7.2 \%$ : one-way ANOVA, $F_{(2,75)}=0.6, p=0.521$ ) were not significantly different following ilPFC activation. In contrast, inactivation of the ilPFC produced an opposite effect on DA neuron population activity. After infusion of TTX into the ilPFC ( $n=4$ rats, 42 neurons), DA population activity was nearly double that of controls, with $1.88 \pm 0.14$ cells/track (Fig. $2 B$; one-way ANOVA, $F_{(2,11)}=35.1, p<0.001$; Holm-Sidak post hoc; $t_{(7)}=5.3, p<0.001$ ). Firing rate (Fig. $2 \mathrm{c}$; $\left.3.3 \pm 0.3 \mathrm{~Hz} ; F_{(2,74)}=0.5, p=0.590\right)$ and bursting activity (Fig. $\left.2 D ; 20.5 \pm 3.6 \% ; F_{(2,75)}=0.6, p=0.521\right)$ were not significantly different compared with controls. As with the plPFC, histograms of the distributions of firing rates and burst activity (Fig. 2E,F) did not reveal significant differences among treatment groups (Kolgomorov-Smirnoff test, $p>0.05$ ). In summary, the ilPFC was capable of producing bidirectional effects on DA neuron population activity in the VTA, depending on whether this structure was activated or inactivated. In contrast, the plPFC only attenuated VTA DA neuron population activity.

The effect of infralimbic cortex activation is prevented by inactivation of the basolateral amygdala

The mPFC can affect the VTA via both direct projections to this structure as well as through several indirect pathways. Among these, the mPFC is known to send prominent projections to both 


\section{ilPFC infusions}

A

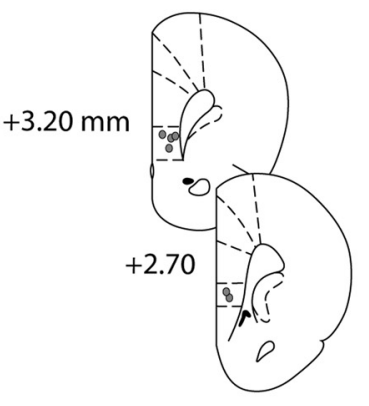

C

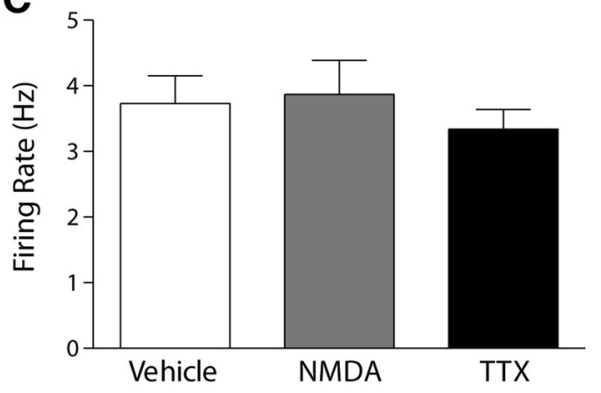

E

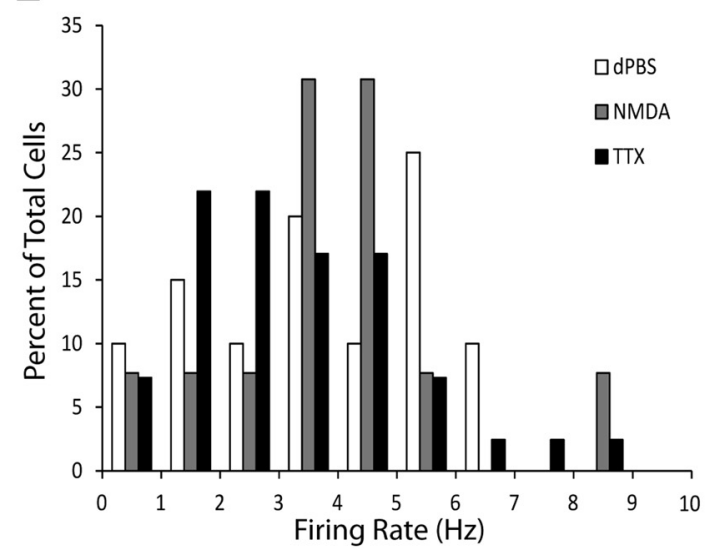

B

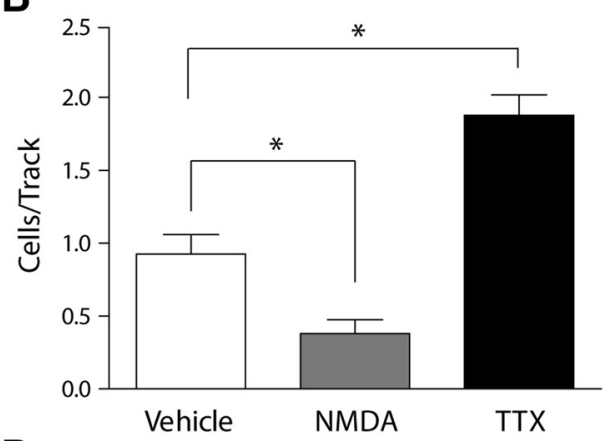

D

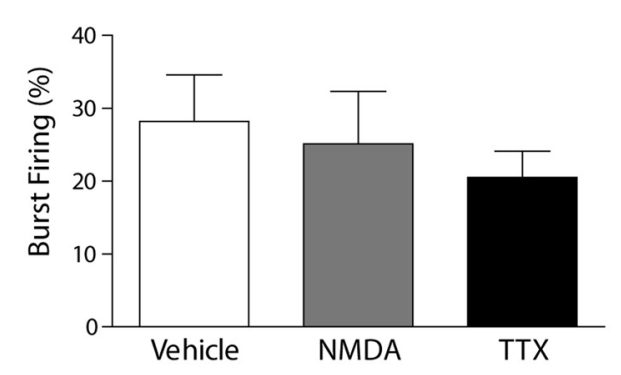

F

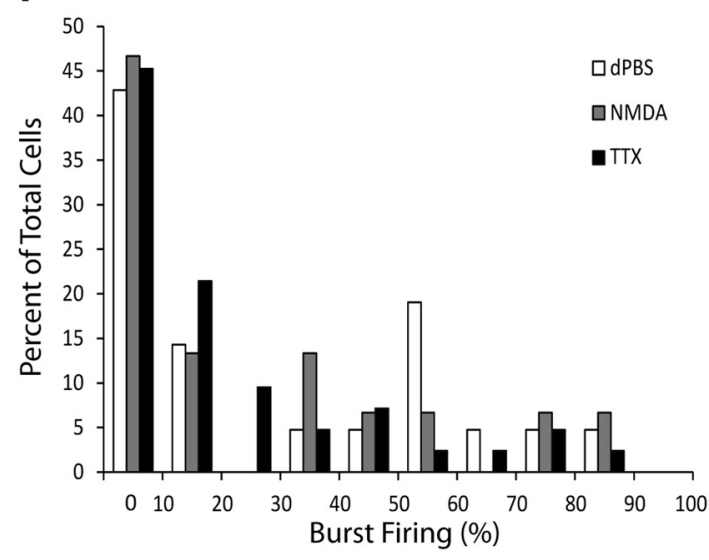

Figure 2. Activation or inactivation of the ilPFC selectively decreases or increases VTA DA neuron population activity, respectively. $\boldsymbol{A}$, Representation of histological placements of infusion cannulae in the ilPFC (circles, $\sim 50 \%$ shown). B, Activating the ilPFC with NMDA resulted in a significant decrease in the number of spontaneously active DA neurons in the VTA (cells/track, gray bar), whereas inactivating the IIPFC with TTX yielded a significant increase in the number of spontaneously active DA neurons in the VTA (black bar), compared with vehicle injections (white bar). $\boldsymbol{C}, \boldsymbol{D}$, Infusion of vehicle (white bars), NMDA (gray bars), or TTX (black bars) led to no changes in the firing rate or percentage of spikes in bursts in dopaminergic cells in the VTA. Distributions of firing rate $(\boldsymbol{E})$ and the percentage of burst firing $(\boldsymbol{F})$ were not affected significantly by infusions of NMDA or TTX (Kolgomorov-Smirnoff test). ${ }^{*} p<0.05$ (one-way ANOVA, Holm-Sidak post hoc test). $n=4$ or 5 rats/group; $n=15-42$ neurons/group. Data are represented as mean \pm SEM.

the BLA and the entorhinal cortex, which regulates vSub activity (Vertes, 2006). Given that previous studies found that vSub activation only produced increases in VTA DA neuron population activity whereas inactivation of this structure had no effect on population activity (Floresco et al., 2003), a potential role for the BLA in the ilPFC attenuation of VTA DA neuron activity was examined. This was done by pharmacological inactivation of the BLA while simultaneously activating the ilPFC and evaluating its effects on midbrain DA neuron activity. In rats receiving infusion of dPBS vehicle in both the ilPFC and the BLA ( $n=5$ rats, 30 neurons), the average DA population activity was $1.03 \pm 0.12$ cells/track with an average firing rate of $4.0 \pm 0.5 \mathrm{~Hz}$ and $25.8 \pm$ $5.9 \%$ of the action potentials being fired in bursts (Fig. 3B-D). VTA activity after ilPFC activation and dPBS infusion in the BLA ( $n=5$ rats, 18 neurons) produced effects consistent with those observed with NMDA infusion into the ilPFC performed previously, in that the DA population activity was decreased to $0.58 \pm$ 0.05 cells/track (Fig. $3 B$; two-way ANOVA, $F_{(1,16)}=7.8, p=$ 0.013; Bonferroni post hoc: $\left.t_{(8)}=3.6, p=0.014\right)$. The average firing rate (Fig. $3 C$; $4.1 \pm 0.39 \mathrm{~Hz}$; two-way ANOVA, $F_{(1,123)}=$ $0.4, p=0.510$ ) and percentage of spikes in bursts (Fig. $3 D ; 32.9 \pm$ $7.1 \%$; two-way ANOVA, $F_{(1,123)}=1.0, p=0.322$ ) were not significantly different from control conditions. Inactivation of the BLA with TTX while infusing dPBS in the ilPFC ( $n=5$ rats, 38 neurons) did not change any measured parameters of VTA DA activity. Overall population activity was found to be $1.19 \pm 0.10$ cells/track (Fig. $3 B$ ), which was not significantly different from the double-vehicle control test (two-way ANOVA, $F_{(1,16)}=17.1$, $p<0.001$; post hoc Bonferonni $t$ test; $t_{(8)}=1.3, p=1.000$ ). Average firing rate (Fig. $3 C ; 4.0 \pm 0.29 \mathrm{~Hz}$; two-way ANOVA, 


\section{ilPFC/BLA infusions}

A
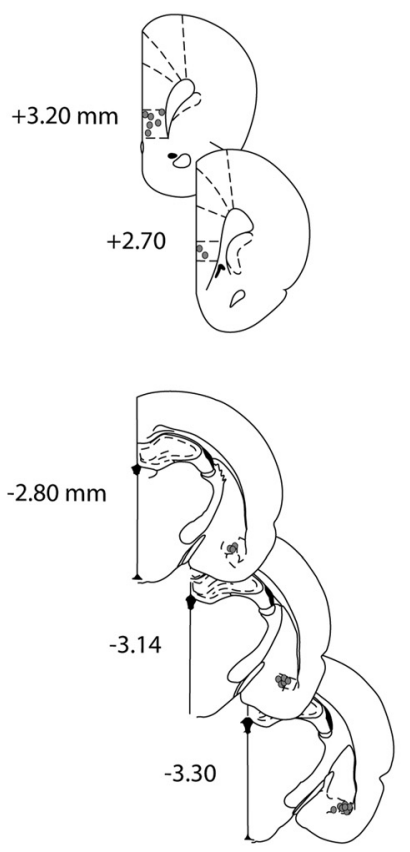

B

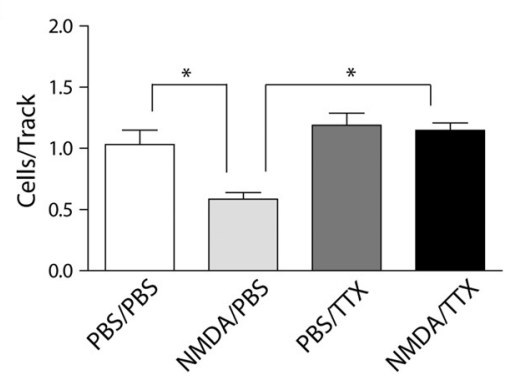

C

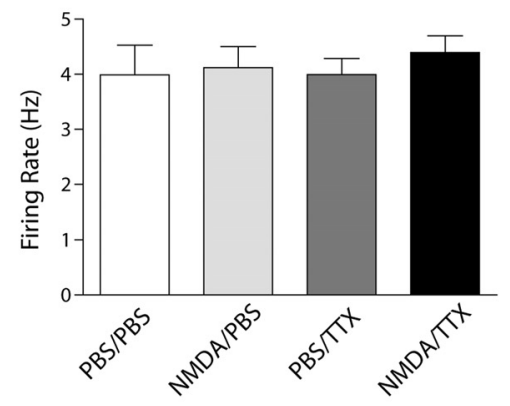

D

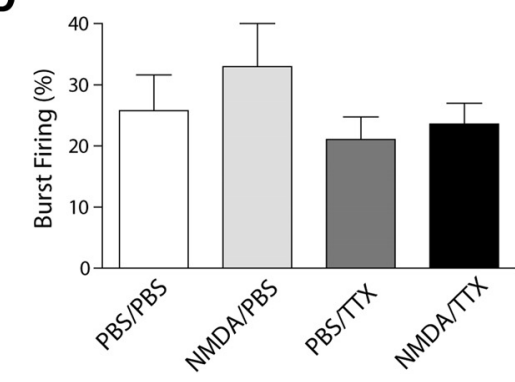

Figure 3. The ilPFC activation-induced decrease in VTA DA neuron population activity is mediated via the BLA. $A$, Histological placement of infusion cannulae into the IPFC and BLA (circles, 50\% of ilPFC placements [top] shown for clarity and 100\% of BLA placements [bottom] shown). $\boldsymbol{B}$, Dual infusions of NMDA into the ilPFC and TTX into the BLA (black bar) prevented the decrease in number of spontaneously active dopamine cells in the VTA that occurred with activation of the ilPFC alone (cells/track, light gray bar). Inactivating the BLA alone did not yield any changes in dopamine population activity compared with vehicle infusions (dark gray bar and white bar, respectively). $\boldsymbol{C}, \boldsymbol{D}$, The firing rate and percentage of spikes occurring in bursts were not affected by any of the infusions. ${ }^{*} p<0.05$ (two-way ANOVA, Bonferroni post hoc test). $n=5$ rats/group; $n=18-41$ neurons/group. Data are represented as mean \pm SEM.

$\left.F_{(1,123)}=0.1, p=0.727\right)$ was also not significantly altered, nor was bursting activity (Fig. 3D; $21.1 \pm 3.7 \%$; two-way ANOVA, $\left.F_{(1,123)}=2.1, p=0.151\right)$. The decrease in population activity found after ilPFC activation was prevented by simultaneous inactivation of the BLA. The average number of spontaneously active DA cells after ilPFC infusion of NMDA and BLA infusion of TTX (Fig. $3 B ; n=5$ rats, 41 neurons) was $1.15 \pm 0.06$ cells/ track, which was significantly greater than that observed after ilPFC infusion of NMDA along with vehicle infusion in the BLA. There was a significant interaction between infusion locations (two-way ANOVA, $\mathrm{df}=19 ; F_{(1,16)}=5.4, p=0.034$ ), and a post hoc Bonferroni $t$ test confirmed the effect of BLA infusion of TTX versus $\mathrm{dPBS}\left(t_{(8)}=4.6, p=0.002\right)$. Furthermore, this result was found to be not significantly different from the double-vehicle control (one-way ANOVA: $F_{(3,16)}=10.1, p=0.220$ ). Average firing rate (Fig. $3 C ; 4.4 \pm 0.3 \mathrm{~Hz}$; two-way ANOVA, $F_{(1,123)}=0.1$, $p=0.733$ ) and percentage of spikes occurring in bursts (Fig. 3D; $23.6 \pm 3.4 \%$; two-way ANOVA,: $\left.F_{(1,123)}=0.2, p=0.630\right)$ were not altered compared with other groups. Thus, although BLA inactivation alone was not sufficient to elicit a change in VTA DA activity, inactivation of this region prevented the substantial decrease in VTA DA neuron population activity observed after ilPFC activation. Overall DA population activity was the only parameter affected by these manipulations.

\section{The effect of infralimbic cortex inactivation is prevented by} inactivation of the ventral subiculum In this study, we show that the BLA mediates the decrease in VTA DA neuron population activity after ilPFC activation, whereas inactivation of the BLA alone had no effect. In contrast, previous studies showed that activation of the vSub will increase VTA DA neuron population activity, whereas inactivation of this structure was without effect on overall population activity (Floresco et al., 2001). Therefore, we examined whether the vSub plays a role in the activation of VTA DA neuron population activity after inactivation of the ilPFC. The activity state of VTA DA neurons after vehicle infusion in both the ilPFC and vSub ( $n=5$ rats, 31 neurons) was comparable with that observed in all other control groups. The overall DA population activity of the VTA was $1.03 \pm$ 0.14 cells/track, with these cells firing at an average frequency of $3.6 \pm 0.4 \mathrm{~Hz}$ and with $26.6 \pm 4.8 \%$ of these action potentials occurring in bursts (Fig. $4 B-D$ ). Inactivation of the ilPFC by TTX while infusing dPBS into the vSub $(n=6$ rats, 49 neurons) yielded results similar to those observed after infusion of TTX into the ilPFC alone, in that the average number of spontaneously active DA neurons was increased to $1.57 \pm 0.09$ cells/track (Fig. $4 B$; two-way ANOVA, $F_{(1,17)}=2.8$, $p=0.011$; Bonferroni post hoc: $t_{(9)}=3.8$, $p=0.008)$, a significant increase from double-vehicle control. Firing frequency (Fig. $4 C ; 3.9 \pm 0.2 \mathrm{~Hz}$; two-way ANOVA, $F_{(1,137)}=$ $3.5, p=0.062$ ) and percentage of spikes in bursts (Fig. $4 D ; 19.0 \pm$ $4.0 \%$; two-way ANOVA, $\left.F_{(1,137)}=0.5, p=0.465\right)$ were not significantly different from control. Inactivation of the vSub with TTX and ilPFC infusion of dPBS ( $n=5$ rats, 32 neurons) did not significantly affect VTA DA neuron activity. The number of spontaneously active DA neurons (Fig. $4 B ; 1.03 \pm 0.06$; two-way ANOVA, $F_{(1,17)}=12.5, p=0.003$; Bonferroni post hoc: $t_{(8)}=0.1$, $p=1.000$ ), average firing rate (Fig. $4 C ; 3.5 \pm 0.26 \mathrm{~Hz}$; two-way ANOVA, $\left.F_{(1,137)}=2.0, p=0.159\right)$, and percentage of spikes in bursts (Fig. $4 D ; 22.3 \pm 3.7$; two-way ANOVA, $F_{(1,137)}=1.8, p=$ 0.188 ) were not significantly different from double-infusion controls. This is consistent with previous findings (Floresco et al., 2001; Lodge and Grace, 2007), where inactivation of the vSub did not significantly alter VTA DA neuron activity. Inactivation of the vSub prevented the increase in DA neuron population activity observed after ilPFC inactivation. VTA population activity after TTX inactivation of both the ilPFC and the vSub ( $n=5$ rats, 29 
neurons) was $0.83 \pm 0.14$ cells/track (Fig. $4 B$ ), which was significantly less than the increased VTA DA neuron population activity observed after inactivation of the ilPFC alone. The interaction between ilPFC and vSub infusion was significant (twoway ANOVA, $\left.F_{(1,17)}=13.1, p=0.002\right)$, as was the effect of vSub inactivation within the ilPFC inactivation groups (Bonferroni post hoc: $\left.t_{(8)}=5.2, p<0.001\right)$. In addition, the population activity observed in this treatment was found to be not significantly different from control (one-way ANOVA, $\left.F_{(3,17)}=10.2, p=0.211\right)$. Firing rate (Fig. $4 C ; 4.6 \pm 0.3 \mathrm{~Hz}$; two-way ANOVA, $\left.F_{(1,137)}=3.3, p=0.071\right)$ was not significantly different from other groups, nor was bursting activity (Fig. $4 D ; 34.6 \pm$ $3.9 \%$; two-way ANOVA, $F_{(1,137)}=5.0$, $p=0.027$; Bonferroni post hoc: $t_{(58)}=2.6$, $p=0.069)$. The increase in DA neuron population activity observed after inactivation of the ilPFC by TTX was prevented by vSub inactivation, although no other parameters were altered. In contrast, as with the BLA, vSub inactivation alone did not affect mesolimbic DA neuron activity.

\section{Discussion}

The data presented here indicate that the ilPFC is capable of exerting bidirectional control over midbrain DA neuron output by altering the population activity of DA neurons in the VTA. Furthermore, we show that decreases in population activity caused by activation of the ilPFC can be prevented by inactivation of the BLA, and increases caused by inactivation of the ilPFC can be attenuated by inactivation of the vSub. Additionally, the plPFC may be involved in further control of the VTA, as inactivation the plPFC resulted in a decrease of DA population activity. Each of these pathways appears to exert unique but opposite actions, in that neither inactivation of the vSub nor the BLA results in an alteration of VTA DA neuron population activity (Floresco et al., 2001; Lodge and Grace, 2006a; Chang and Grace, 2013), which is consistent with what we have seen here. Of course, it should be noted that these regions typically show low levels of baseline activity in the anesthetized rat. It is likely that, in an awake behaving rat, such alterations may indeed alter DA neuron activity states. It is also unclear from the data presented whether the brain regions studied are the only relevant nodes in the circuit. Although our data show that the effects of the mPFC on DA neuron activity are dependent on the BLA and the vSub, it is unknown whether this occurs via direct projections to/from the regions involved or may involve other brain systems as well. Nonetheless, the BLA and vSub appear to be necessary for the effects of the mPFC on DA neuron activity states. Indeed, we have shown that the vSub involves a multisynaptic circuit through the accumbens and ventral pallidum to affect DA neuron population activity (Floresco et al., 2003).

\section{ilPFC/vSub infusions}

A

B

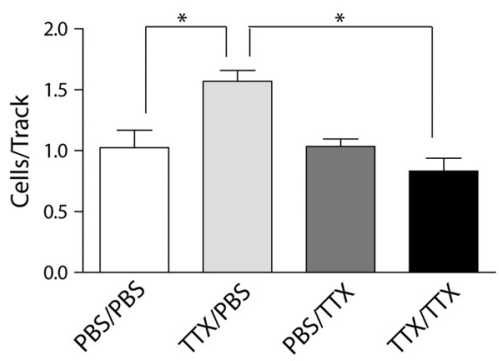

C

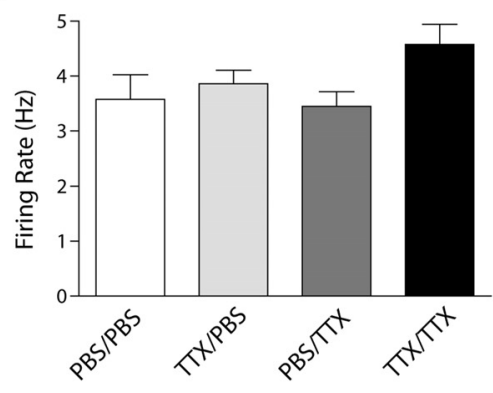

D

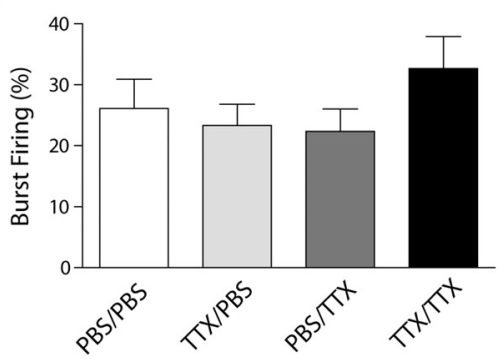

Figure 4. The ilPFC inactivation-induced increase in VTA DA neuron population activity is mediated via the vSub. $\boldsymbol{A}$, Histological rate and percentage of spikes occurring in bursts were not affected by any of the infusion treatments. ${ }^{*} p<0.05$ (two-way ANOVA, Bonferroni post hoc test). $n=5$ or 6 rats/group; $n=29-49$ neurons/group. Data are represented as mean \pm SEM.

These data are consistent with a model whereby inactivation of the ilPFC leads to hyperactivity of the vSub, resulting in an increase in the number of DA neurons that are spontaneously active, as has been seen in previous studies where the ventral hippocampus has been activated directly (Lodge and Grace, 2006b; Lodge, 2011) (Fig. 5). Although it has been reported that electrical stimulation of the mPFC did not affect VTA DA neuron activity (Lodge, 2011), the authors did not distinguish between ilPFC and plPFC, and coactivation of both regions could potentially cancel out an observed action. The mPFC, however, does not project directly to the vSub; there are direct excitatory projections from this region to the entorhinal cortex, as well as excitatory projections to the nucleus reunions (Vertes, 2006), both of which in turn provide powerful excitatory influence over the vSub (Vertes, 2006). In contrast, the BLA appears to only exert an attenuation of DA neuron activity. Thus, the hypoactivity observed in the VTA after activation of the ilPFC with NMDA is dependent on activation of the BLA. The BLA also appears to exert a direct effect on DA, in that electrical stimulation of the 


\section{Normal state}

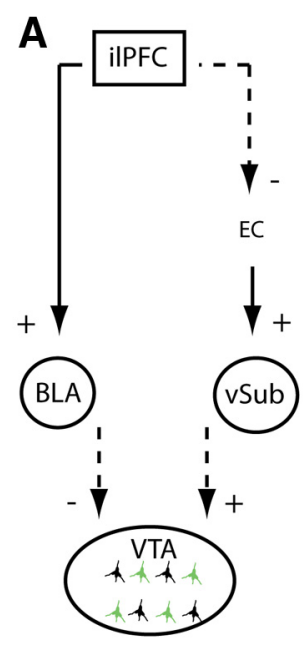

Direct connection $\longrightarrow$
Multisynaptic $\longrightarrow$

Figure 5. Diagram representing two proposed pathways through which the IIPFC could act to modulate the activity of DA neurons in the VTA. $A$, Normal pathway without any manipulation to any regions shows the normal population activity in the VTA (green colored neurons indicate spontaneously active DA cells). $\boldsymbol{B}$, Activation of the ilPFC with NMDA (green circle) leads to a decrease in population activity (red downward arrow) in the VTA via activation of the BLA pathway (thicker lines and green upward arrow). Dashed lines from the BLA to the VTA indicate that this pathway has not yet been delineated. $\boldsymbol{C}$, Inactivation of the iIPFC with TTX (red circle) leads to an increase in population activity in the VTA (green upward arrow) potentially through attenuation of an indirect inhibitory pathway from the ilPFC to the entorhinal cortex (EC), leading to an increase in vSub firing and VTA population activity (green upward arrows). The dashed line from the vSub to the VTA indicates a multisynaptic pathway that includes the nucleus accumbens and ventral pallidum (Floresco et al., 2003).

BLA is reported to increase DA overflow in the nucleus accumbens (Jackson and Moghaddam, 2001); however, this has been reported to result from presumed presynaptic effects within the accumbens rather than changes in DA neuron activity (Floresco et al., 1998). It is important to note that none of the manipulations resulted in an alteration of average firing rate or burst firing patterns. This is not to state that there were not differences in firing rate or pattern of individual neurons; however, an average change across the population was not observed, nor was the distribution of firing rates or bursting altered. A change in DA neuron population activity is likely to have substantial behavioral consequences. We have shown previously that DA population activity increases are associated with increased behavioral responses to amphetamine across different conditions ( Lodge and Grace, 2008a, b; Cifelli and Grace, 2012; Valenti et al., 2012; Chang and Grace, 2013). Burst firing has been characterized as the behaviorally salient signal of the VTA to indicate phasic, rapid behavioral significance (Grace, 1991; Schultz, 1998). However, we have shown that a DA neuron must be firing spontaneously to emit a phasic burst (Floresco et al., 2003; Lodge and Grace, 2006a). Therefore, by controlling the number of DA neurons firing, the ilPFC can control the amplitude of the phasic signal (Grace, 2012). Tonic population activity appears to act as the gain of the VTA (i.e., the level of responsivity [stimulus-evoked burst firing] of the DA neuron population). It is as of yet unclear why activation of the ilPFC only activates BLA projecting neurons and not vSub projecting neurons, or vice versa. One possibility is that there may be a change of sign in the PFC-vSub pathway, such that activation of the ilPFC will activate the BLA and simultaneously inactivate the vSub, and vice versa. This type of competition would be consistent with that seen within the nucleus accumbens with vSub versus mPFC activation (Goto and Grace, 2005). Furthermore, although anesthesia would attenuate cortical activity, the finding that inactivation of the ilPFC produces opposite effects of activation suggests that at least some baseline activity is present to be suppressed or enhanced.

In this study, we chose to use pharmacological activation of selective regions within the brain rather than using electrical stimulation. This was because of the specific advantages of using pharmacological activation: (1) electrical stimulation would very likely result in antidromic activation of a number of cortical and subcortical regions that could affect DA neuron activity and confound our results; (2) pharmacological activation allows the system to be activated according to the membrane properties and firing characteristics of the neurons (e.g., burst firing, firing frequency, nonsynchronous firing); and (3) electrical stimulation over an extended period is likely to show tachyphylaxis and potential tissue damage. Furthermore, the specificity of the pharmacological infusion can be demonstrated by the opposite effects observed with drugs acting in opposite manners on neuronal activity (i.e., TTX vs NMDA) or in adjacent regions (i.e., ilPFC vs plPFC). We did not find changes in average firing rate and pattern; however, others (Murase et al., 1993) found that chemical stimulation of the mPFC can result in changes in burst firing in individual DA neurons. Although it is likely that, on the individual neuron level, firing pattern changes may be occurring after the performed infusions, this was not evident on the averaged rate and pattern data. Moreover, although Enomoto et al. (2011) have reported that GABA antagonist bicuculline increased burst firing when infused into the plPFC, there may be differences in how NMDA activation and GABA antagonism affect the excitatory output of the $\mathrm{mPFC}$.

The work presented here is consistent with previous studies, which show that the ilPFC's control over tonic activity of the VTA may be altered in an anhedonic state that occurs during depression or bipolar disorder (Padrão et al., 2013; Zahodne et al., 2012). Anhedonia is the inability to derive pleasure from normally pleasurable activities. Several studies link altered DA activity with anhedonic states, both in humans (Wise, 2008) and in rodents (Wise et al., 1978). Imaging studies have shown that the human analog of the ilPFC is hyperactive in depression (Mayberg et al., 2000); moreover, the amygdala is hyper-responsive to negative stimuli in depression (Kalia, 2005; Leppänen, 2006). As we have observed low tonic firing of the VTA after activation of the ilPFC, it may be that hyperactivity in the ilPFC (or the human correlate, the subgenual anterior cingulate cortex, BA 25) could lead to an anhedonic condition. Altered ilPFC activity could further exacerbate depression by interfering with the evaluation of controllability of stressors and the appropriate expression of avoidance behaviors (Amat et al., 2005; Moscarello and LeDoux, 2013). We have found that depression-like behaviors in animal models are regulated through the BLA (Chang and Grace, 2013). Interestingly, inactivation of the plPFC produced opposite effects 
on VTA DA neurons compared with the ilPFC. Thus, with plPFC inactivation, there was a decrease in the number of DA neurons firing, whereas activation of the plPFC had no effect. The mechanism by which the plPFC affects VTA DA neuron activity is not clear at this time. There are several possibilities, such as a removal of plPFC attenuation of vSub activity or removal of plPFC inhibition of the ilPFC. Although the mechanism is not known, there are substantial data to show that the plPFC and ilPFC have opposite effects behaviorally (Vidal-Gonzalez et al., 2006; SierraMercado et al., 2011). Whether this inhibitory interaction occurs via known direct projections between these regions (Vertes, 2004; Hoover and Vertes, 2007) or via interactions at the vSub (Vertes, 2006) or other subcortical regions requires further investigation.

In contrast, decreases in ilPFC activity lead to increased DA neuron population activity. Indeed, such a condition of increased DA response may be related to an opposite condition, such as mania. Mania is categorized as a period of persistently elevated, expansive, or irritable mood (American Psychiatric Association, 2000). Moreover, mania shares some of the DA-related characteristics of schizophrenia, such as delusions and hallucinations (Perich et al., 2013) and responsivity to DA antagonist drugs (Tohen and Vieta, 2009; Cruz et al., 2010). There is some evidence to suggest that DA dysfunction may play a key role in mania (Park and Kang, 2013). Indeed, some aspects of mania can be modeled in rodents using single administration of high-dose psychostimulants, resulting in increased extracellular DA concentrations (Lyon and Satz, 1991). Inactivating the ilPFC resulted in a large increase in tonic activity. Previous work has indicated that hyperactivity in the ventral hippocampus, and more specifically the vSub, can be the underlying cause of such an increase, as is likely the case in schizophrenia and amphetamine sensitization. In addition, in the case of the MAM schizophrenia model (Lodge and Grace, 2008a), amphetamine sensitization (Lodge and Grace, 2008a), and with ilPFC inactivation, it was possible to return VTA population activity levels to normal by inactivating the vSub. These data support the idea that the overdrive of the VTA that is caused by ilPFC inactivation could be acting through a pathway involving the vSub. This gives rise to the provocative hypothesis that instability either (1) within the ilPFC, in which it switches from hypoactive to hyperactive states, or (2) an alternation in dominance between the ilPFC and plPFC, could present as an underlying pathological condition in bipolar disorder.

\section{References}

Amat J, Baratta MV, Paul E, Bland ST, Watkins LR, Maier SF (2005) Medial prefrontal cortex determines how stressor controllability affects behavior and dorsal raphe nucleus. Nat Neurosci 8:365-371. CrossRef Medline

American Psychiatric Association (2000) Diagnostic and statistical manual of mental disorders, Ed 4 (Text Revision). American Psychiatric Association: Washington, DC.

Bora E, Fornito A, Yücel A, Pantelis C (2010) Voxelwise meta-analysis of gray matter abnormalities in bipolar disorder. Biol Psychiatry 67:10971105. CrossRef Medline

Brooks JO 3rd, Bonner JC, Rosen AC, Wang PW, Hoblyn JC, Hill SJ, Ketter TA (2009) Dorsolateral and dorsomedial prefrontal gray matter density changes associated with bipolar depression. Psychiatry Res 172:200-204. CrossRef Medline

Chang CH, Grace AA (2013) Amygdala $\beta$-noradrenergic receptors modulate delayed downregulation of dopamine activity following restraint. J Neurosci 33:1441-1450. CrossRef Medline

Cifelli P, Grace AA (2012) Pilocarpine-induced temporal lobe epilepsy in the rat is associated with increased dopamine neuron activity. Int J Neuropsychopharmacol 15:957-964. CrossRef Medline

Cruz N, Sanchez-Moreno J, Torres F, Goikolea JM, Valentí M, Vieta E (2010) Efficacy of modern antipsychotics in placebo-controlled trials in bipolar depression: a meta-analysis. Int J Neuropsychopharmacol 13:5-14. CrossRef Medline

Daberkow DP, Brown HD, Bunner KD, Kraniotis SA, Doellman MA, Ragozzino ME, Garris PA, Roitman MF (2013) Amphetamine paradoxically augments exocytotic dopamine release and phasic dopamine signals. J Neurosci 33:452-463. CrossRef Medline

Enomoto T, Tse MT, Floresco SB (2011) Reducing prefrontal $\gamma$-aminobutyric acid activity induces cognitive, behavioral, and dopaminergic abnormalities that resemble schizophrenia. Biol Psychiatry 69:432-441. CrossRef Medline

Espana RA, Jones SR (2013) Presynaptic dopamine modulation by stimulant self-administration. Front Biosci (Schol Ed) 5:261-276.

Floresco SB, Yang CR, Phillips AG, Blaha CD (1998) Basolateral amygdala stimulation evokes glutamate receptor-dependent dopamine efllux in the nucleus accumbens of the anaesthetized rat. Eur J Neurosci 10:12411251. CrossRef Medline

Floresco SB, Todd CL, Grace AA (2001) Glutamatergic afferents from the hippocampus to the nucleus accumbens regulate activity of ventral tegmental area dopamine neurons. J Neurosci 21:4915-4922. Medline

Floresco SB, West AR, Ash B, Moore H, Grace AA (2003) Afferent modulation of dopamine neuron firing differentially regulates tonic and phasic dopamine transmission. Nat Neurosci 6:968-973. CrossRef Medline

Gabbott PL, Warner TA, Jays PR, Salway P, Busby SJ (2005) Prefrontal cortex in the rat: projections to subcortical autonomic, motor, and limbic centers. J Comp Neurol 492:145-177. CrossRef Medline

Gill KM, Lodge DJ, Cook JM, Aras S, Grace AA (2011) A novel alpha5GABA(A)R-positive allosteric modulator reverses hyperactivation of the dopamine system in the MAM model of schizophrenia. Neuropsychopharmacology 36:1903-1911. CrossRef Medline

Goto Y, Grace AA (2005) Dopamine-dependent interactions between limbic and prefrontal cortical plasticity in the nucleus accumbens: disruption by cocaine sensitization. Neuron 48:255-266. CrossRef Medline

Grace AA (1991) Phasic versus tonic dopamine release and the modulation of dopamine system responsivity: a hypothesis for the etiology of schizophrenia. Neuroscience 41:1-24. CrossRef Medline

Grace AA (2012) Dopamine system dysregulation by the hippocampus: implications for the pathophysiology and treatment of schizophrenia. Neuropharmacology 62:1342-1348. CrossRef Medline

Grace AA, Bunney BS (1983) Intracellular and extracellular electrophysiology of nigral dopaminergic neurons: 1 . Identification and characterization. Neuroscience 10:301-315. CrossRef Medline

Grace AA, Bunney BS (1984) The control of firing pattern in nigral dopamine neurons: burst firing. J Neurosci 4:2877-2890. Medline

Hoogenboom WS, Perlis RH, Smoller JW, Zeng-Treitler Q, Gainer VS, Murphy SN, Churchill SE, Kohane IS, Shenton ME, Iosifescu DV (2013) Feasibility of studying brain morphology in major depressive disorder with structural magnetic resonance imaging and clinical data from the electronic medical record: a pilot study. Psychiatry Res 211:202-213. CrossRef Medline

Hoover WB, Vertes RP (2007) Anatomical analysis of afferent projections to the medial prefrontal cortex in the rat. Brain Struct Funct 212:149-179. CrossRef Medline

Hu M, Li J, Eyler L, Guo X, Wei Q, Tang J, Liu F, He Z, Li L, Jin H, Liu Z, Wang J, Liu F, Chen H, Zhao J (2013) Decreased left middle temporal gyrus volume in antipsychotic drug-naive, first-episode schizophrenia patients and their healthy unaffected siblings. Schizophr Res 144:37-42. CrossRef Medline

Jackson ME, Moghaddam B (2001) Amygdala regulation of nucleus accumbens dopamine output is governed by the prefrontal cortex. J Neurosci 21:676-681. Medline

Kalia M (2005) Neurobiological basis of depression: an update. Metabolism 54:24-27. CrossRef Medline

Keedwell P, Drapier D, Surguladze S, Giampietro V, Brammer M, Phillips M (2009) Neural markers of symptomatic improvement during antidepressant therapy in severe depression: subgenual cingulate and visual cortical repsonses to sad, but not happy, facial stimuli are correlated with changes in symptom score. J Psychopharmacol 23:775-788. CrossRef Medline

Koester P, Tittgemeyer M, Wagner D, Becker B, Gouzoulis-Mayfrank E, Daumann J (2012) Cortical thinning in amphetamine-type stimulant users. Neuroscience 221:182-192. CrossRef Medline

Ledoux AA, Phillips JL, Labelle A, Smith A, Bohbot VD, Boyer P (2013) Decreased fMRI activity in the hippocampus of patients with schizophre- 
nia compared to healthy control participants, tested on a wayfinding task in a virtual town. Psychiatry Res 211:47-56. CrossRef Medline

Leppänen JM (2006) Emotional information processing in mood disorders: a review of behavioral and neuroimaging findings. Curr Opin Psychiatry 19:34-39. CrossRef Medline

Lim CS, Baldessarini RJ, Vieta E, Yucel M, Bora E, Sim K (2013) Longitudinal neuroimaging and neuropsychological changes in bipolar disorder patients: review of the evidence. Neurosci Biobehav Rev 37:418-435. CrossRef Medline

Lodge DJ (2011) The medial prefrontal and orbitofrontal cortices differentially regulate dopamine system function. Neuropsychopharmacology 36 : 1227-1236. CrossRef Medline

Lodge DJ, Grace AA (2006a) The hippocampus modulates dopamine neuron responsivity by regulating the intensity of phasic neuron activation. Neuropsychopharmacology 31:1356-1361. CrossRef Medline

Lodge DJ, Grace AA (2006b) The laterodorsal tegmentum is essential for burst firing of ventral tegmental area dopamine neurons. Proc Natl Acad Sci U S A 103:5167-5172. CrossRef Medline

Lodge DJ, Grace AA (2008a) Amphetamine activation of hippocampal drive of mesolimbic dopamine neurons: a mechanism of behavioral sensitization. J Neurosci 28:7876-7882. CrossRef Medline

Lodge DJ, Grace AA (2008b) Hippocampal dysfunction and disruption of dopamine system regulation in an animal model of schizophrenia. Neurotox Res 14:97-104. CrossRef Medline

Lyon N, Satz P (1991) Left turning (swivel) in medicated chronic schizophrenia patients. Schizophr Res 4:53-58. CrossRef Medline

Mayberg HS, Brannan SK, Tekell JL, Silva JA, Mahurin RK, McGinnis S, Jerabek PA (2000) Regional metabolic effects of fluoxetine in major depression: serial changes and relationship to clinical response. Biol Psychiatry 48:830-843. CrossRef Medline

Moscarello JM, LeDoux JE (2013) Active avoidance learning requires prefrontal suppression of amygdala-mediated defensive reactions. J Neurosci 33:3815-3823. CrossRef Medline

Murase S, Grenhoff J, Chouvet G, Gonon FG, Svensson TH (1993) Prefrontal cortex regulates burst firing and transmitter release in rat mesolimbic dopamine neurons studies in vivo. Neurosci Lett 157:53-56. CrossRef Medline

Overton PG, Tong ZY, Clark D (1996) A pharmacological analysis of the burst events induced in midbrain dopaminergic neurons by electrical stimulation of the prefrontal cortex in the rat. J Neural Transm 103:523540. CrossRef Medline

Padrão G, Mallorquí A, Cucurell D, Marco-Pallares J, Rodriguez-Fornells A (2013) Neurophysiological differences in reward processing in anhedonics. Cogn Affect Behav Neurosci 13:102-115. CrossRef Medline

Park SY, Kang UG (2013) Hypothetical dopamine dynamics in mania and psychosis: its pharmacokinetic implications. Prog Neuropsychopharmacol Biol Psychiatry 43:89-95. CrossRef Medline

Paxinos G, Watson C (2007) The rat brain in stereotaxic coordinates, Ed 6. London, UK: Academic.

Perich T, Mitchell PB, Loo C, Hadzi-Pavlovic D, Roberts G, Frankland A, Lau P, Wright A (2013) Clinical and demographic features associated with the detection of early warning signs in bipolar disorder. J Affect Disord 145:336-340. CrossRef Medline
Schultz W (1998) The phasic reward signal of primate dopamine neurons. Adv Pharmacol 42:686-690. Medline

Sesack SR, Carr DB (2002) Selective prefrontal cortex inputs to dopamine cells: implications for schizophrenia. Physiol Behav 77:513-517. CrossRef Medline

Sexton CE, Mackay CE, Ebmeier KP (2013) A systematic review and metaanalysis of magnetic resonance imaging studies in late-life depression. Am J Geriatr Psychiatry 21:184-195. CrossRef Medline

Shan D, Lucas EK, Drummond JB, Haroutunian V, Meador-Woodruff JH, McCullumsmith RE (2013) Abnormal expression of glutamate transporters in temporal lobe areas in elderly patients with schizophrenia. Schizophr Res 144:1-8. CrossRef Medline

Sierra-Mercado D, Padilla-Coreano N, Quirk GJ (2011) Dissociable roles of prelimbic and infralimbic cortices, ventral hippocampus, and basolateral amygdala in the expression and extinction of conditioned fear. Neuropsychopharmacology 36:529-538. CrossRef Medline

Singh MK, Chang KD, Chen MC, Kelley RG, Garrett A, Mitsunaga MM, Bararpour L, Howe M, Reiss AL, Gotlib IH (2012) Volumetric reductions in the subgenual anterior cingulate cortex in adolescents with bipolar I disorder. Bipolar Disord 14:585-596. CrossRef Medline

Tohen M, Vieta E (2009) Antipsychotic agents in the treatment of bipolar mania. Bipolar Disord 11 [Suppl 2]:45-54.

Treadway MT, Zald DH (2011) Reconsidering anhedonia in depression: lessons from translational neuroscience. Neurosci Biobehav Rev 35:537555. CrossRef Medline

Ungless MA, Grace AA (2012) Are you or aren't you? Challenges associated with physiologically identifying dopamine neurons. Trends Neurosci 35: 422-430. CrossRef Medline

Valenti O, Gill KM, Grace AA (2012) Different stressors produce excitation or inhibition of mesolimbic dopamine neuron activity: response alteration by stress pre-exposure. Eur J Neurosci 35:1312-1321. CrossRef Medline

Vertes RP (2004) Differential projections of the infralimbic and prelimbic cortex in the rat. Synapse 51:32-58. CrossRef Medline

Vertes RP (2006) Interactions among the medial prefrontal cortex, hippocampus and midline thalamus in emotional and cognitive processing in the rat. Neuroscience 142:1-20. CrossRef Medline

Vidal-Gonzalez I, Vidal-Gonzalez B, Rauch SL, Quirk GJ (2006) Microstimulation reveals opposing influences of prelimbic and infralimbic cortex on the expression of conditioned fear. Learn Mem 13:728-733. CrossRef Medline

Wise RA (2008) Dopamine and reward: the anhedonia hypothesis 30 years on. Neurotox Res 14(2-3):169-183.

Wise RA, Spindler J, deWit H, Gerberg GJ (1978) Neuroleptic-induced “anhedonia" in rats: primozide blocks reward quality of food. Science 201: 262-264. CrossRef Medline

Zahodne LB, Bernal-Pacheco O, Bowers D, Ward H, Oyama G, Limotai N, Velez-Lago F, Rodriguez RL, Malaty I, McFarland NR, Okun MS (2012) Are selective serotonin reuptake inhibitors associated with greater apathy in Parkinson's disease? J Neuropsychiatry Clin Neurosci 24:326-330. CrossRef Medline 